\title{
O modelo da tabuada na proposição davydoviana
}

\author{
The multiplication table model by Davýdov
}

Josélia Euzébio Rosa ${ }^{1}$. Ediséia Suethe Faust Hobold ${ }^{2}$

Resumo: Davýdov, doutor em Psicologia e seguidor de Vygotski, coordenou o processo de elaboração de uma proposta para o ensino de Matemática na Rússia, a partir dos fundamentos da Teoria HistóricoCultural. Tal proposição foi publicada por meio de livros didáticos e manuais de orientação ao professor. Esse material constituiu a fonte de dados da pesquisa apresentada neste artigo, cujo objetivo foi investigar o modelo da relação essencial da tabuada na proposição davydoviana. Para tanto, selecionamos três tarefas do material didático davydoviano, cuja análise possibilitou revelar os elementos que constituem a essência da tabuada e como estes se relacionam e conformam o modelo universal em um sistema de representações objetal, gráfica e literal.

Palavras-chave: Teoria histórico-cultural. Davýdov. Proposição de ensino. Educação matemática. Tabuada.

\begin{abstract}
Davýdov, PhD in Psychology and Vygotsky's follower, coordinated a proposal for Mathematics teaching in Russia, based on Historical-Cultural Theory assumptions. The proposal was published by means of textbooks and teacher's guides. This material constitutes the data source for the present research. The aim is investigate the model of the essential relationships of multiplication within Davýdov's proposal. Therefore, we selected three teaching tasks from the teaching material based on Davýdov assumptions. Its analysis enabled us to reveal the elements that constitute the essence of the multiplication table and how they are connected and form a universal model represented as an object, graphically and in text.
\end{abstract}

Keywords: Historical-cultural theory. Davýdov. Teaching proposition. Mathematics education. Multiplication table.

\footnotetext{
${ }^{1}$ Universidade do Sul de Santa Catarina (Unisul), Tubarão, SC, Brasil. E-mail: <joselia.euzebio@yahoo.com.br>.

${ }^{2}$ Rede Estadual de Educação de Santa Catarina, Brasil.
} 


\section{Introdução}

O descompasso entre o atual desenvolvimento científico e tecnológico e a escola, a necessidade de maiores reflexões sobre a formação inicial e continuada dos profissionais da educação, plano de carreira no magistério, e a desvalorização profissional têm contribuído com parte dos problemas relacionados com a educação escolar. Porém, outro aspecto tão relevante quanto os apresentados anteriormente incide nos processos de ensino e aprendizagem dos estudantes: nos conteúdos e métodos que regem esses dois processos (DAVÝDOV, 1982). Consequentemente, na especificidade da Educação Matemática, muitos estudantes não se apropriam de conceitos básicos, como adição, subtração, multiplicação, divisão, entre outros. Eles apenas memorizam os algoritmos, de forma mecânica. Durante a resolução de problemas, os estudantes apresentam dificuldades na identificação da operação a ser realizada e, quando a identificam, cometem equívocos na operacionalização de seu algoritmo (GALDINO, 2016; MATOS, 2017). Tais resultados são constatados em pesquisas científicas (CRESTANI, 2016; GALDINO, 2016; HOBOLD, 2014; ROSA; FLORES, 2015) e no relatório da Avaliação Nacional da Alfabetização (ANA)³.

Por que muitos alunos não se apropriam de conceitos tão básicos? O que tem dificultado a aprendizagem significativa dos estudantes? Dentre as diversas causas está, também, o conteúdo e o método subjacente ao modo de organização do ensino que predomina atualmente no Brasil, sustentado nos fundamentos da lógica formal tradicional (BERNARDES, 2011; HOBOLD, 2014; ROSA; DAMAZIO; SILVEIRA, 2014).

A estruturação dos conceitos fundamentada nessa lógica tem início na operação prática-objetiva, por meio da observação das características externas de um grupo de objetos, dados sensorialmente aos órgãos dos sentidos. A análise consiste em abstrair algumas características gerais e substanciais imprescindíveis. O conceito é elaborado com base na aparência externa, nas características comuns aos vários objetos observados externamente. Por meio do processo de comparação de vários objetos, o homem destaca as propriedades comuns (indícios), que os tornam semelhantes entre si. Assim, “[...] segundo certos indícios comuns (iguais), os objetos singulares podem se associar em determinado conjunto ou classe" (DAVÝDOV, 1982, p. 46, tradução nossa).

Ao designar os indícios comuns, substanciais, por meio de palavras, atinge-se o conceito. Este procedimento de conhecimento é denominado por Davýdov $(1982,1988)$ de empírico. A definição de conceito, de acordo com a lógica formal, “[...] é a forma pela qual se refletem as características essenciais dos objetos” (ROSENTAL, 1962, p. 133, tradução nossa). A essência são as características comuns, imprescindíveis a vários objetos de determinado grupo, as que garantem a elaboração do conceito. Porém, essas características são dadas diretamente aos órgãos dos sentidos. Não há uma análise mais profunda sobre as relações internas que o conceito apresenta. Deste modo, a lógica do conceito é a "[...] lógica da essência", dada a partir da aparência externa do objeto (LEFEBVRE, 1991, p. 142). O ensino organizado nessa lógica desenvolve o pensamento intuitivo, empírico (DAVÝDOV, 1982, 1988).

\footnotetext{
${ }^{3}$ Resultado disponível em: <http://ana.inep.gov.br/ANA/>. Acesso em: 20 maio 2016.
} 
O pensamento empírico é útil para atividades simples, do dia-a-dia das pessoas, mas não condiz com o atual desenvolvimento científico e tecnológico sustentado no pensamento teórico contemporâneo. Este se desenvolve durante a apropriação humana dos conceitos científicos, no ensino organizado a partir dos princípios da lógica dialética correspondente à Teoria Histórico-Cultural.

Davýdov, a partir dos fundamentos da Teoria Histórico-Cultural, elaborou uma base teórico-metodológica que reúne princípios psicológicos em função de objetivos pedagógicos e didáticos, que promovam o desenvolvimento do pensamento teórico dos estudantes. Para o autor em referência, o desenvolvimento do pensamento teórico requer a reprodução da essência do objeto de conhecimento. A essência

[...] é a conexão interna que, como fonte única, como base genética, determina todas as outras especificidades particulares do todo. Trata-se de conexões objetivas, as que, em sua dissociação e manifestação, asseguram a unidade dos aspectos do todo, isto é, dão ao objeto um caráter concreto. (DAVÍDOV, 1988, p. 147, tradução nossa).

Desse modo, enquanto a essência é extraída das relações externas dos objetos no pensamento empírico, no teórico ela é revelada a partir da conexão interna dos referidos objetos. De acordo com os fundamentos da lógica dialética, a relação essencial dos conceitos, depois de revelada durante o experimento objetal, é modelada por meio de um sistema de símbolos. $\mathrm{Na}$ especificidade da Matemática, esses símbolos podem ser de natureza aritmética, geométrica e algébrica (ROSA, 2012). A revelação da essência de cada conceito, no contexto de inter-relação das significações aritméticas, algébricas e geométricas, possibilita a introdução dos conceitos, no ensino, por meio de sistemas conceituais (VIGOTSKI, 2000), onde cada conceito está internamente conectado com outros. Foi nesta perspectiva que Davýdov e colaboradores, seguidores de Vigotski, elaboraram uma proposta para o ensino de Matemática.

Entre os anos de 1959 e 1983, Davýdov trabalhou, juntamente com Elkonin, no Instituto de Psicologia Geral e Pedagogia da Academia de Ciências Pedagógicas da União Soviética. Inicialmente como colaborador científico, em seguida como chefe de laboratório de psicologia e, finalmente, como diretor. Neste período constituiu sua própria equipe de pesquisadores, na Escola Experimental N. 91 (SHUARE, 1990). Davýdov (АABЫАOB), juntamente com alguns colaboradores, como Gorbov (ГОРБОВ), Mikulina (МИКУ АИНА) e Savieliev (САВЕ АЬЕВА), elaboraram e desenvolveram com estudantes, em caráter investigativo, uma proposição para o Ensino de Matemática. A partir dos resultados da pesquisa teórica e experimental, elaboraram livros didáticos, manuais de orientação ao professor, entre outros.

As reflexões sobre a experiência realizada em sala de aula pelo grupo de colaboradores de Davýdov possibilitaram um amplo processo de elaboração e reelaboração da proposta. Esse movimento é refletido nos manuais de orientação ao professor, em forma de relato de experiência. Sem essas reflexões, não é possível conceber as tarefas apresentadas no livro didático como expressão dos pressupostos oriundos da Teoria Histórico-Cultural, pois, aparentemente, as tarefas davydovianas são semelhantes aos exercícios apresentados nos livros didáticos brasileiros.

O livro didático davydoviano apresenta vários objetos de ensino da Matemática, tais como adição, subtração, multiplicação, divisão, sistemas de numeração (binário, ternário, qua- 
ternário, decimal), resolução de problemas, equações, entre outros. Dentre eles, optamos pela tabuada, uma vez que ela ainda constitui um dos obstáculos durante a realização de cálculos na disciplina de Matemática em nosso país (GALDINO, 2016; HOBOLD, 2014; ROSA; FLORES, 2015). Mais especificamente, investigamos o modelo da relação essencial da tabuada subjacente às tarefas apresentadas na proposição davydoviana.

Trata-se de uma investigação bibliográfica, cuja referência de análise consiste nas tarefas ${ }^{4}$ davydovianas para o ensino da tabuada. Tais tarefas foram extraídas da versão original dos livros didáticos (no idioma russo) equivalentes ao segundo e terceiro anos do Ensino Fundamental brasileiro (DAVÝDOV et al., 2009, 2012), respectivamente. Apresentamos a resolução das tarefas em conformidade com os manuais de orientação ${ }^{5}$ ao professor da referida proposição de ensino. As tarefas estão escritas em russo, e a análise das mesmas foi realizada com o auxílio da professora de língua russa Elvira Kim.

No primeiro contato com o material didático davydoviano, detectamos algumas tarefas que indicavam a existência de sistematização da tabuada nos livros do segundo e terceiro ano do Ensino Fundamental. A proposição davydoviana não é apresentada de forma fragmentada por conceitos. Os conceitos são apresentados em um sistema de conexões, no qual a subtração é introduzida a partir da relação interna com a adição. Esta também subsidia a introdução da multiplicação e da tabuada. Neste movimento, um conceito contribui para o desenvolvimento do outro, e conformam um sistema integral.

Adotamos os seguintes procedimentos metodológicos: inicialmente, identificamos a orientação metodológica apresentada nos manuais de orientação ao professor, correspondente às tarefas apresentadas nos livros didáticos. Na sequência, procedemos ao estudo concomitante das tarefas com as orientações, base para a identificação de que Davýdov e colaboradores desenvolvem a tabuada a partir de um sistema conceitual (conceito de número, relação de multiplicidade, divisibilidade, relação parte-todo, adição, subtração, entre outros). Entretanto, para o presente artigo, selecionamos apenas três tarefas e as reproduzimos fidedignamente, inclusive com a resolução proposta nos manuais de orientação ao professor. A análise possibilitou revelar o modelo da relação universal da tabuada, na proposição davydoviana, conforme segue.

\section{Tarefas davydovianas}

A relação universal do objeto, na lógica dialética, é revelada por meio de modelos. Neles, a estrutura do objeto é reproduzida. O modelo é "uma forma peculiar de abstração, na qual as relações essenciais do objeto estão fixadas nos nexos, e relações visualmente perceptíveis e representadas, de elementos materiais e semióticos" (DAVÍDOV, 1988, p. 134, tradução nossa).

\footnotetext{
${ }^{4}$ Correspondente aos exercícios ou atividades nos livros didáticos brasileiros.

${ }^{5} \mathrm{Na}$ proposição davydoviana são obras distintas, para cada livro didático há um respectivo livro de orientação ao professor.
} 
A modelação constitui o trabalho com a relação interna. Na especificidade da Matemática, consiste na essência do objeto em diferentes formas, tais como objetal, gráfica ou literal. Trata-se da representação das relações entre grandezas, sejam elas discretas ou contínuas. Grandezas são as propriedades dos objetos que permitem determinar seu tamanho: maior, menor, igual, enfim, sua medida. Para cada conceito há uma relação diferente entre as grandezas que lhe dá origem.

Na proposição davydoviana, os fundamentos para o conceito de tabuada são expressos pela necessidade de determinar um valor consideravelmente maior que a unidade de medida disponível. Nestes casos, a utilização direta da unidade de medida é trabalhosa. Por isso, é necessário utilizar outra, maior que a inicial. No entanto, esta nova unidade de medida não é dada, será construída sob a orientação do professor. Para tal construção, o professor apresenta uma folha, na qual estão desenhados quatro (4) retângulos de tamanhos e cores diferentes para recortar $^{6}$ (DAVÝDOV et al., 2009), conforme Figura 1.

Figura 1. Kit para recorte

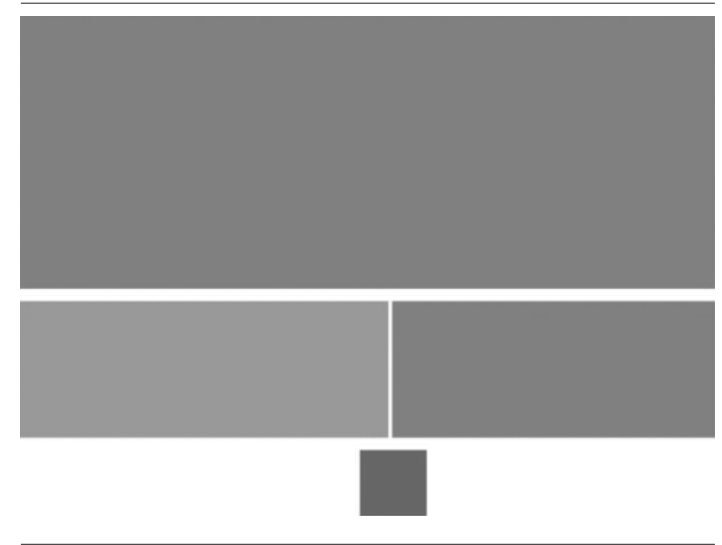

Fonte: Adaptado de Davýdov et al. (2012).

A primeira tarefa tem por base os recortes apresentados na Figura 1. Trata-se do experimento objetal, o ponto de partida para a revelação dos elementos que constituem a essência do conceito de multiplicação e, consequentemente, da tabuada.

Tarefa 1: a partir dos recortes, construir uma figura com área de superfície igual ao recorte que somente o professor tem em mãos (Figura 2).

\footnotetext{
${ }^{6}$ Este material é apresentado no final do livro didático davydoviano. Caso o leitor tenha interesse em reproduzir a tarefa, as medidas das áreas dos retângulos apresentados no kit são: $1,5 \mathrm{~cm} \times 1,5 \mathrm{~cm} ; 6 \mathrm{~cm}$ x $15 \mathrm{~cm} ; 3 \mathrm{~cm} \times 7 \mathrm{~cm}$; $3 \mathrm{~cm}$ x $8 \mathrm{~cm}$. Porém, vale ressaltar que, em momento algum, durante o desenvolvimento das tarefas com o kit, o professor menciona tais medidas, apenas sua representação literal.
} 
Figura 2. Tarefa 1, recorte ( $3 \mathrm{~cm} \times 4,5 \mathrm{~cm})$ que somente o professor tem em mãos

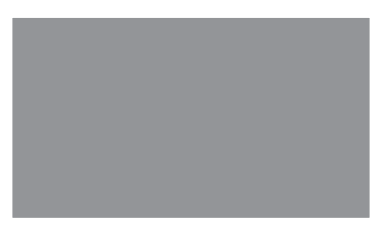

Fonte: Adaptado de Davýdov et al. (2012).

Este recorte (Figura 2) não se encontra no kit apresentado anteriormente. No entanto, os recortes do kit auxiliarão na medição, durante o processo de confecção da figura proposta. Este movimento ocorre sob a orientação do professor.

A medida da superfície a ser construída é representada genericamente por $C$. Sua composição tem, como referência, os recortes que compõem o kit. Inicialmente, faz-se a comparação das áreas das figuras para verificar se elas constam no kit. O professor informa que a medida da área em construção segue o esquema ${ }^{7}$ de seta, conforme a Figura 3.

Figura 3. Tarefa 1, registro da medida $C$

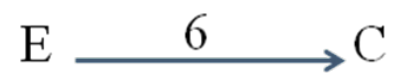

Fonte: Adaptado de Davýdov et al. (2012).

De acordo com o esquema (Figura 3), a unidade de medida $E$ (o menor recorte do kit) cabe seis (6) vezes na grandeza com medida $C$ (medida em construção). No processo de resolução da tarefa, faz-se necessário promover a seguinte reflexão: para obter medidas iguais é necessário que todos utilizem a mesma unidade de medida, e o resultado da medição será registrado por meio do esquema com seta. Com a unidade de medida $E$, constrói-se a superfície de área $C$, conforme Figura 4.

\footnotetext{
${ }^{7} \mathrm{O}$ esquema é um modo de organizar o movimento do pensamento no processo de elaboração conceitual na proposição davydoviana.
} 
Figura 4. Tarefa 1, construção da superfície de área $C$

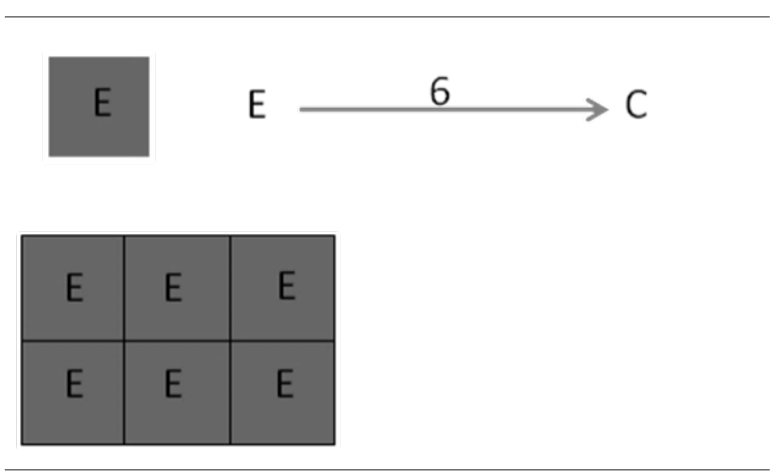

Fonte: Adaptado de Davýdov et al. (2012).

A essência da tarefa consiste na relação entre duas áreas e a quantidade de vezes que uma cabe na outra. Essa relação de multiplicidade dá origem ao conceito de multiplicação e, consequentemente, da tabuada. Além disso, em uma única tarefa são contempladas significações aritmética (quantidade de vezes que a unidade de medida coube na grandeza em medição), algébrica (representação genérica da medida da grandeza), e geométrica (áreas, esquema).

Tais elementos foram revelados durante a construção da área de uma superfície com unidades de medida pré-determinadas. O foco é para o processo de elaboração de uma grandeza com medida maior, a partir de uma unidade de medida menor, com base nas informações apresentadas no esquema. O mesmo ocorre na tarefa seguinte, mas com uma nova necessidade.

Tarefa 2: A tarefa propõe a construção da superfície com medida A, que somente o professor tem nas mãos. Para tanto, o professor propõe que se utilize a mesma unidade de medida da tarefa anterior $(E)$, e faz o seguinte registro no quadro: $E \rightarrow A$. Assim, a área da superfície com medida A será construída a partir da unidade de medida $E$ (Figura 5). Faz-se necessário determinar a medida de $A$ em relação à unidade de medida $E$.

Figura 5. Tarefa 2, superfície de área $A$, unidade de medida $E$, e o registro com seta

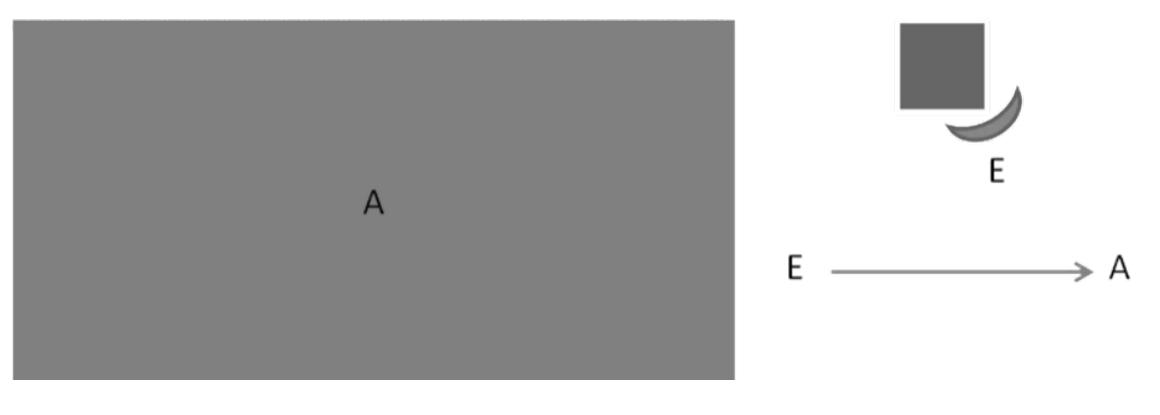

Fonte: Adaptado de Davýdov et al. (2012). 
O professor fixa o recorte modelo no quadro $(A)$ e inicia o processo de medição com a unidade de medida $E$ (Figura 6). Enquanto isso, faz anotações e lamenta o quão incômodo é trabalhar com uma unidade de medida tão pequena. Propositalmente, deixa a unidade de medida cair e esquece quantas medidas já foram utilizadas (DAVÝDOV et al., 2009).

Figura 6. Tarefa 2, processo de medição

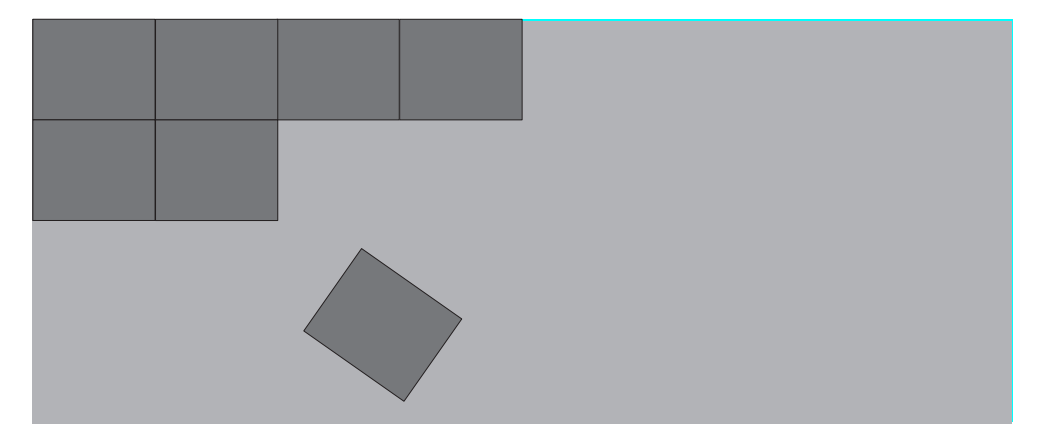

Fonte: Adaptado de Davýdov et al. (2012).

Por fim, o professor, intencionalmente, simula perder a paciência e propõe a utilização de uma unidade de medida maior, para agilizar o processo de medição ${ }^{8}$. A nova unidade de medida é denominada de P (Figura 7). Ele faz a medição e informa o resultado: quatro (4). Isto é, a nova unidade de medida (P) cabe quatro (4) vezes na superfície com medida $A$. Antes, a unidade de medida considerada era E; agora, a unidade de medida é $P$. O novo resultado não pode ser registrado no esquema inicial $(E \rightarrow A)$. Isso requer um novo esquema que registre o resultado da medição da superfície de medida $A$, com unidade de medida $P(P \rightarrow A)$. Acima da seta, o professor escreve o número quatro.

Contudo, as crianças desconhecem que elas não têm, em seus kits, recortes para a unidade de medida $P$ : há apenas dois deles semelhantes $(3 \mathrm{~cm} \times 8 \mathrm{~cm}$ e $3 \mathrm{~cm} \times 7 \mathrm{~cm})$. O professor os compara com a unidade de medida $P$ e as crianças concluem que a unidade de medida $P$ é menor que os recortes do kit, conforme a Figura 8.

O professor questiona sobre a possibilidade de ainda utilizar a unidade de medida pequena $(E)$, e enfatiza que o ideal seria a adoção da unidade de medida $P$, por ser maior. Mas, como proceder? Todos têm em comum a unidade de medida pequena (unidade E), adotada na tarefa anterior; porém, agora desejam utilizar uma unidade de medida maior. O professor toma a unidade de medida E e mostra que ela cabe oito (8) vezes em $P$ (Figura 9). A partir desta informação, as crianças iniciam a construção da área da superfície $P$.

\footnotetext{
${ }^{8}$ Vale reafirmar que a resolução das tarefas, por nós apresentada, é fundamentada no manual de orientação ao professor, que é constituído por relatos de experiência realizados em sala de aula por mais de 25 anos.
} 
Figura 7. Tarefa 2, apresentação de uma nova unidade de medida

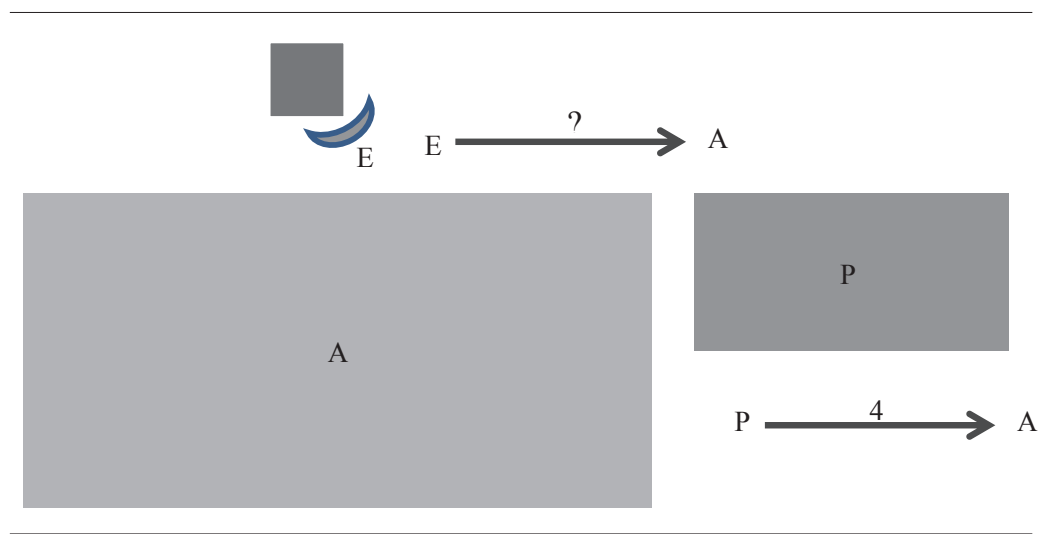

Fonte: Adaptado de Davýdov et al. (2012).

Figura 8. Tarefa 2, comparação da área da superfície da unidade de medida $P$ com os recortes do kit

\section{$\mathrm{P}$}

Fonte: Adaptado de Davýdov et al. (2012).

Figura 9. Tarefa 2, construção da unidade de medida intermediária $P$
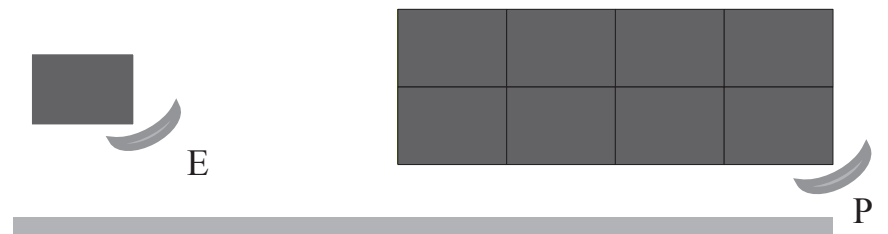

A

Fonte: Adaptado de Davýdov et al. (2012). 
Conforme o professor havia informado, a unidade de medida $P$ cabe quatro (4) vezes na superfície com medida $\mathrm{A}$. Com base nesta informação, as crianças constroem a figura $A$, conforme a Figura 10. (DAVÝDOV et al., 2009).

Figura 10. Tarefa 2, construção da área da superfície $A$

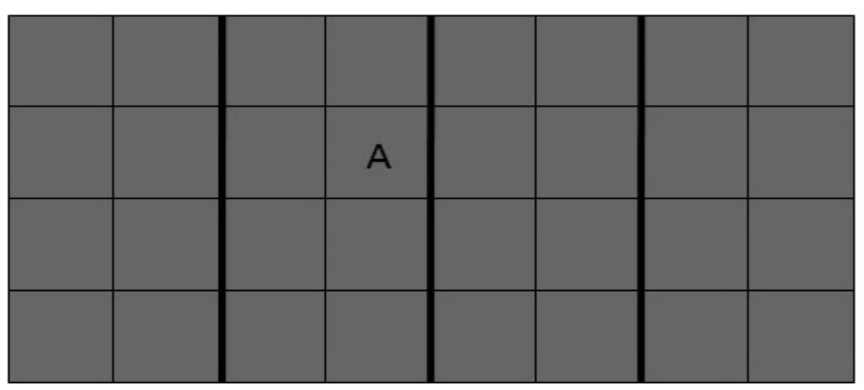

Fonte: Adaptado de Davýdov et al. (2012).

Depois da construção da superfície $A$, o professor esquematiza, no quadro, o processo de desenvolvimento da tarefa: tínhamos em comum a unidade de medida $E$; a partir dela, precisávamos construir a área com medida $A$. Ao falar, registra-se no quadro o esquema $(E \rightarrow$ A), conforme Figura 11.

Figura 11. Tarefa 2, construção do esquema

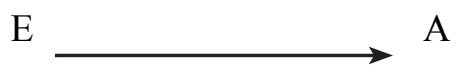

Fonte: Adaptado de Davýdov et al. (2012).

Porém, essa unidade de medida não foi apropriada para a medição, por ser pequena demais, se comparada à superfície a ser construída. Então, com a unidade de medida $E$ construímos uma nova unidade $(P)$, composta por oito (8) unidades de medidas básicas $(E)$. Ao falar, o professor acrescenta, no esquema, mais uma seta $(E \rightarrow P)$, e escreve o número oito (8) ao lado esquerdo da nova seta, conforme a Figura 12.

Com a unidade de medida $P$ construímos a superfície $A$. Ela é constituída por quatro (4) unidades de medida intermediária $(P)$. Esta nova etapa do processo de resolução é representada, no esquema, com uma nova seta. Ao lado direito da terceira seta registra-se o número de vezes que a unidade de medida intermediária $(P)$ coube na superfície $A$, como indica a Figura 13. (DAVÝDOV et al., 2009). 
Figura 12. Tarefa 2, construção do esquema

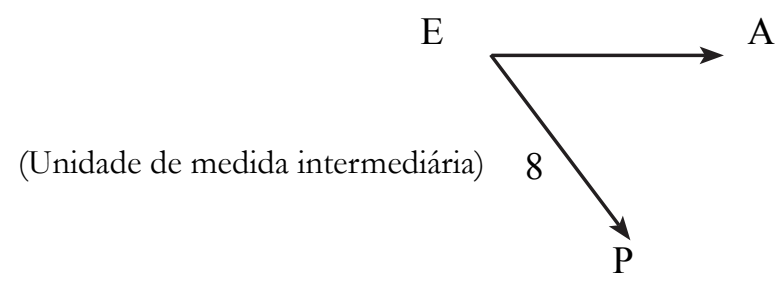

A

Fonte: Adaptado de Davýdov et al. (2012).

Figura 13. Tarefa 2, o esquema é o início da modelação gráfica

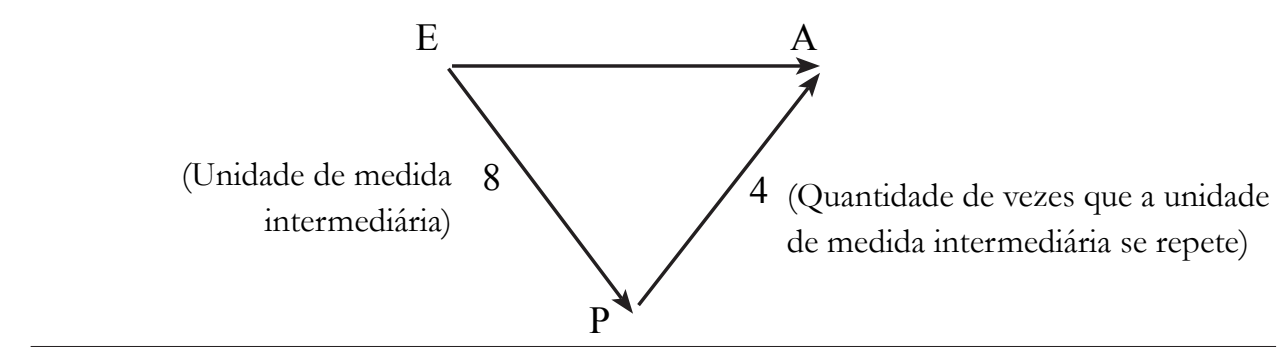

Fonte: Elaborado pelas autoras.

A unidade de medida É é denominada de unidade de medida básica; e $P$, de unidade de medida intermediária. O procedimento adotado durante o procedimento de resolução da tarefa torna o processo de medição mais cômodo, quando a unidade de medida básica é consideravelmente menor que a grandeza a ser medida. Com esta condição, torna-se menos trabalhosa a adoção de uma unidade de medida maior. O esquema anterior sintetiza o movimento percorrido durante a resolução da tarefa, no que se refere à construção da unidade de medida intermediária e a medida $A$.

A tarefa possibilita a transformação dos dados a fim de revelar a essência da multiplicação e da tabuada. Tanto para o sistema conceitual de multiplicação e divisão (HOBOLD, 2014) quanto, por extensão, para a tabuada, estão ligados à unidade básica, à unidade intermediária e ao total de unidades básicas e intermediárias. São elas que compõem a essência do conceito de tabuada e permeiam todas as tarefas particulares. A essência é modelada, inicialmente, na forma objetal-sensorial (relação entre as áreas) e, a partir de então, na forma gráfica (esquema).

A partir do incômodo gerado pelo processo de medição com a unidade de medida $E$ (Figura 6), surgiu a necessidade da introdução de uma unidade maior (Figura 9), denominada de unidade de medida intermediária. Assim, o ponto de partida, na proposição davydoviana, é 
a observação e transformação dos dados reais da tarefa, não solucionáveis pelos procedimentos conhecidos pela criança. A finalidade é revelar e distinguir "uma relação completamente definida de certo objeto integral” (DAVÍDOV, 1988, p. 182, tradução nossa), na especificidade deste, a tabuada. Tal relação é constituída pelos dados da tarefa e atua como fonte de todas as tabuadas (do objeto integral).

Esclarecemos que a transformação dos dados ocorre em várias tarefas particulares. Em algumas, são consideradas as grandezas discretas; em outras, as contínuas. Deste modo, as unidades de medida são unidades de comprimento, áreas, volumes, entre outros. Além disso, as unidades básicas, compostas ou não, são transformadas em unidades intermediárias. Essa variedade de grandezas e de unidades de medida evita, de acordo com Davýdov (1982), a generalização empírica do conceito.

A representação da relação essencial, na forma objetal e gráfica, é parte do processo de modelação. Em outras palavras, os dados (unidades de medida básica e intermediária e o total delas) são modelados na forma objetal por meio da construção da área da superfície $A$ (Figura 10). Em seguida, os mesmos dados foram modelados, na forma gráfica, por meio do esquema de setas (Figura 13). O movimento inicial de abstração da relação essencial da tabuada, do modelo, culminará, após o desenvolvimento de várias tarefas particulares, com sua representação por meio de letras. Os modelos não são

[...] simples substitutos dos objetos. As condições de criação, por exemplo, de um modelo material [objetal], são tais que "em seus elementos e nas relações entre eles, estão separadas e fixadas as vinculações essenciais e necessárias que formam uma estrutura completamente determinada" ( $\mathrm{SH}$ TOFF, 1966, p. 281). Os modelos são uma forma peculiar de abstração, na qual as relações essenciais do objeto estão fixadas nos nexos e relações visualmente perceptíveis e representadas, de elementos materiais e semióticos (DAVÍDOV, 1988, p. 134, tradução nossa, grifos do autor).

O estudo do modelo constitui o "[...] trabalho interno imprescindível no processo de apropriação dos conceitos teóricos e dos procedimentos generalizados de ação" (DAVÍDOV, 1988, p. 182, tradução nossa). A percepção do

[...] modelo material [objetal] pressupõe, simultaneamente, uma participação significativa do pensamento, a aplicação dos conhecimentos teóricos e da experiência acumulados. Ao perceber o modelo, o experimentador compreende o que ocorre nele. (SHTOFF, 1966 apud DAVÍDOV, 1988, p. 133, tradução nossa).

Ressaltamos que o processo de modelação da relação essencial, nas várias formas de representação, não se restringe a uma tarefa única, particular: ao contrário, estende-se a várias tarefas da proposição davydoviana. É importante afirmar que a reprodução da relação essencial da tabuada, na forma objetal e gráfica, é o estágio inicial para chegarmos à expressão literal do modelo universal, conforme apresentamos na tarefa 3 a seguir. 
Tarefa 3: Calcule cada produto por meio das propriedades comutativa e distributiva ${ }^{9}$ (DAVÍDOV et al., 2009):

$$
\begin{array}{ll}
4 \times 1= & 4 \times 6= \\
4 \times 2= & 4 \times 7= \\
4 \times 3= & 4 \times 8= \\
4 \times 4= & 4 \times 9= \\
4 \times 5= & 4 \times 10=
\end{array}
$$

As operações referentes à resolução da tabuada são organizadas em determinada sequência, e representam a tabuada do número quatro (4). O professor direciona a atenção para três multiplicações conhecidas $(4 \times 1=\ldots, 4 \times 2=\ldots$ e $4 \times 3=\ldots)$. Os resultados são, respectivamente, 4, 8 e 12. (DAVÝDOV et al., 2009).

O professor questiona: "Como podemos determinar o produto da próxima multiplicação $4 \mathrm{x}$ 4) sem utilizar a calculadora e a régua? É possível utilizar a propriedade distributiva da multiplicação (em relação à soma)?” Após ouvir as sugestões das crianças, o professor recorda a propriedade da multiplicação do número pela soma e questiona: "Como podemos utilizá-la para determinar os próximos produtos?” A sugestão é que o próximo valor desconhecido $(4 \times 4=\ldots)$ seja determinado a partir do último resultado obtido $(4 \times 3=12)$, pois $4 \times 4$ é equivalente a, por exemplo, $4 \times(3$ $+1)$ e $4 \times(2+2)$, conforme segue:

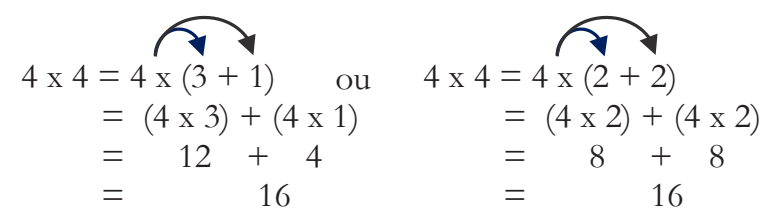

O mesmo procedimento estende-se para o cálculo de $4 \times 5=\ldots$. Isto é, 4 x $5=4 \times$ ( 4 $+1) \rightarrow(4 \times 4)+(4 \times 1)=16+4=20$. O professor enfatiza que os resultados são obtidos a partir do valor comum (quatro). Nos próximos cálculos, o professor adota o registro resumido: $4 \times 6=4 \times(5+1) \rightarrow(4 \times 5)+(4 \times 1)=20+4=24$. Na sequência, o registro é reduzido um pouco mais: $4 \times 7=24+4=28$. Este procedimento é adotado para o cálculo nos próximos fatores: 4 × $8=28+4=32,4 \times 9=32+4=36$ e 4 × $10=36+4=40$ (DAVÝDOV et al., 2009). Ao final, a tabuada é organizada do seguinte modo:

$$
\begin{array}{ll}
4 \times 1=4 & 4 \times 6=24 \\
4 \times 2=8 & 4 \times 7=28 \\
4 \times 3=12 & 4 \times 8=32 \\
4 \times 4=16 & 4 \times 9=36 \\
4 \times 5=20 & 4 \times 10=40
\end{array}
$$

\footnotetext{
${ }^{9}$ Para aprofundar as reflexões sobre o desenvolvimento dessas propriedades, sugerimos a leitura de Hobold (2014).
} 
O professor expõe que, além de construir as tabuadas, também é necessário memorizar seus resultados (DAVÝDOV et al., 2009). A tabuada do número quatro (4) é generalizada do seguinte modo:

$$
\begin{aligned}
4 \times 5 & =4 \times(4+1) \\
4 \times 6 & =4 \times(5+1) \\
& =4 \times(b+1)
\end{aligned}
$$

A determinação de um novo resultado, em que o segundo fator da sentença seja composto pelo fator da sentença anterior $(b)$, mais uma unidade $(b+1)$. Isto traduz o movimento de generalização, em conexão com o da abstração expresso na síntese: o resultado anterior mais quatro. Esta síntese contempla a modelação dos dados na forma literal, referente à tabuada do número quatro: $4 \times(b+1)=c$. Trata-se de uma nova generalização.

Um novo conceito, uma nova generalização não surge senão com base no conceito ou generalização anterior. Isto se manifesta nitidamente no fato de que, paralelamente ao aumento das generalizações algébricas, ocorre o aumento da liberdade de operações. Libertar-se da vinculação ao campo numérico é operação diferente de libertar-se da vinculação do campo visual. A explicação do aumento da liberdade proporcional ao aumento das generalizações algébricas está na possibilidade de um movimento inverso do estágio superior para o inferior, contido na generalização superior: a operação inferior já é vista como caso particular da superior (VIGOTSKI, 2000, p. 372).

Portanto, 4 x $(5+1)$ é um caso particular da generalização superior, expressa no modelo $4 \times(b+1)$. Na expressão literal do modelo universal para a tabuada do número quatro, temos: $4 \mathrm{x}(b+1)=c$. O primeiro termo é fixo (4), e corresponde à medida intermediária. O segundo $(b+1)$ é um operador composto pelo fator da sentença anterior, mais uma unidade de medida intermediária que, neste caso, equivale a quatro. $\mathrm{O}$ operador $(b+1)$ designa quantas vezes a unidade intermediária se repete. Em síntese, o segundo fator de cada sentença (operador) é composto pela soma do termo da sentença anterior, mais uma unidade. Dessas relações, podemos inferir que o segundo fator conforma uma sequência numérica, na especificidade deste estudo, de números positivos $(1,2,3,4, \ldots)$.

Deste modo, Davýdov e colaboradores revelam as características internas, não observáveis diretamente nas grandezas, por meio do modelo da tabuada do número quatro, em interconexão com o modelo universal, válido para todas as tabuadas. Mas, qual é o modelo universal? Para responder a este questionamento, inicialmente, vamos analisar o modelo do conceito de número, $\frac{c}{a}=b$ ou $a \times b=c$. Este é resultado, na proposição davydoviana, das relações entre grandezas. As letras $a, b$ e $c$ assumem os seguintes significados: $c$ representa a grandeza a ser medida, a é a unidade de medida, e $\boldsymbol{b}$ é o número resultante da quantidade de vezes que a unidade de medida cabe na grandeza em medição (ROSA, 2012). A partir do modelo do conceito de número, cuja essência envolve a relação de multiplicidade, Davýdov e colaboradores desenvolveram o modelo da tabuada do número quatro: $a \times \mathrm{x}(b+1)=c$ (Figura 
8). Nele, o primeiro fator de cada sentença é um número fixo (a), e o segundo $(b+1)$ conforma uma sequência de números positivos $(1,2,3,4, \ldots)$.

Em cada operação da sequência que configura a tabuada do número quatro ( $4 \times 1=4$, 4 × $2=8, \ldots)$, o produto do termo seguinte é composto pelo produto da operação anterior $(c)$, mais uma unidade de medida intermediária $(a): c+a$. Este modelo, no contexto da matemática, é denominado de lei da recorrência, pois, para encontrar determinado produto da sequência, "é necessário recorrer ao anterior, o que permite certo grau de generalização". (PANOSSIAN, 2014, p. 124).

Portanto, para expressar a tabuada do número quatro (4), sem recorrer ao termo anterior, precisamos considerar a posição do segundo termo. Em outras palavras, no contexto da proposição davydoviana, é a quantidade de vezes que a unidade de medida é tomada. É possível “[...] encontrar termos da sequência sem que seja necessário escrevê-la completamente" (PANOSSIAN, 2014, p. 124). Neste sentido, os recursos algébricos são fundamentais, pois possibilitam "[...] reconhecer e expressar a lei de formação" (PANOSSIAN, 2014, p. 124).

O modelo particular apresentado na Figura 8, para a tabuada do número quatro, 4 x ( $b$ $+1)$, é expressão do modelo universal válido para qualquer tabuada. Davýdov e colaboradores não o explicitam em sua proposição de ensino. Porém, é tarefa da investigação científica revelar a essência do objeto de estudo, isto é, o universal.

A essência é revelada durante o processo de generalização e abstração desencadeado no desenvolvimento do sistema de tarefas particulares, a partir das relações entre grandezas expressas algebricamente.

$\mathrm{Na}$ especificidade da tabuada, é necessário considerar determinada relação entre grandezas. Nela, os fatores que a compõem ocupam uma posição definida, e conformam uma sequência numérica, na qual cada termo posterior é a soma do anterior, mais uma unidade de medida intermediária, denominada de razão. Subjacente à proposição davydoviana sobre o registro resumido, há a seguinte regularidade:

$$
\begin{gathered}
4 \times 6=4 \times(6-1)+4=24 \\
4 \times 7=4 \times(7-1)+4=28 \\
4 \times 8=4 \times(8-1)+4=32 \\
4 \times 9=4 \times(9-1)+4=36 \\
\vdots \\
a \times n=a \times(n-1)+a=c
\end{gathered}
$$

A partir de um processo de análise das regularidades que possibilitam o registro resumido, revelamos o modelo universal da tabuada. $\mathrm{Na}$ especificidade da tabuada do número quatro (4), temos: $4=\mathbf{a}$; a sequência numérica $6,7,8,9, \ldots=\mathbf{n}$; o produto..., $24,28,32,36, \ldots=\mathbf{c}$.

A modelação da tabuada possibilita ultrapassar os limites dos números naturais e estende-se ao campo dos números racionais, e é válida para qualquer tabuada em particular. O modelo universal "[...] é a lei, a essência dos fenômenos singulares, ou seja, é algo qualitativamente distinto em comparação com a simples soma de características das coisas singulares”. (DAVÝDOV, 1982, p. 243, traduação nossa). A lei “[...] é um dos modos de manifestar a universalidade". (STERNIN, 1965, p. 258). 
O universal está intimamente vinculado com a categoria de essência (STERNIN, 1965). Esta é o aspecto interno que expressa o nexo profundo, que se mantém por meio das várias manifestações particulares. A “[...] essência é aquilo sem o qual o objeto perde sua qualidade específica [...]” (STERNIN, 1965, p. 259). No modelo da tabuada, a essência consiste na relação de multiplicidade entre grandezas (por meio de unidades básicas e intermediárias), cujo resultado conforma uma sequência, na qual o produto posterior é uma unidade de medida intermediária maior que o anterior. Esta essência é expressa no modelo universal $a \times n=a \times(n-1)+a=c$. De acordo com Davýdov (1982), o trabalho com a modelação da relação essencial é imprescindível no processo de desenvolvimento do pensamento e apropriação dos conceitos teóricos.

\section{Considerações finais}

Em síntese, na proposição de ensino davydoviana, a essência da tabuada é constituída pela relação interna entre as unidades de medida básica, intermediária e o total delas, pois a essência é a conexão interna que determina todas as especificidades particulares do objeto. É por meio da relação essencial que o universal se manifesta em forma de lei, conforme o esquema da Figura 14.

Figura 14. Esquema da relação essencial da tabuada

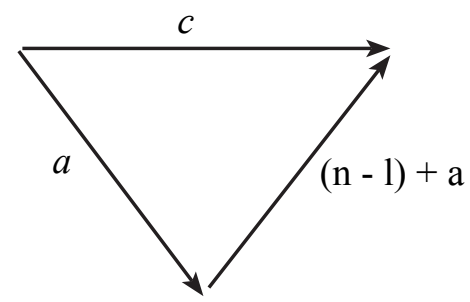

Fonte: Elaborado pelas autoras.

O esquema (Figura 14) representa a essência, a relação inicial que dá origem a todas as tabuadas. No modelo universal da tabuada, $a \mathrm{x}(n-1)+a=c$, o elo que une o universal e o singular é o particular. O particular consiste no número a, na unidade de medida intermediária. Com a variação de $\mathbf{a}$, obtemos as diferentes tabuadas particulares ( $a=4, a=5, a=6, \ldots)$. Mantendo o número a fixo e variando o valor de $\mathbf{n}$, obtêm-se as diferentes singularidades para cada tabuada particular. Tomemos uma particularidade, a tabuada do número oito (8). Ao variarmos $n$, temos as seguintes singularidades: $8 \times 1=8 ; 8 \times 2=16 ; 8 \times 3=24, \ldots$ Assim, a tabuada particular, do número oito (8), por exemplo, surge como resultado da relação universal.

Este movimento conceitual sustenta a proposição davydoviana para o ensino da tabuada, com vistas ao desenvolvimento do pensamento teórico. Enfim, assim como Davýdov (1982), em sua época e em seu país, também vislumbramos, em sua proposição, uma das possibilida- 
des para repensarmos os problemas referentes ao ensino e aprendizagem de Matemática no Brasil, uma vez que muitas proposições brasileiras, de acordo com Rosa (2012), aproximam-se daquelas proposições russas, no que se refere ao predomínio do teor empírico dos conceitos.

\section{Agradecimentos}

A pesquisa que gerou o presente artigo contou com financiamento do Conselho Nacional de Desenvolvimento Científico e Tecnológico (CNPq) e da Fundação de Apoio à Pesquisa Científica e Tecnológica do Estado de Santa Catarina (FAPESC).

\section{Referências}

BERNARDES, M. E. M. A constituição do pensamento na atividade prática: implicações no processo pedagógico. Psicologia em Estudo, Maringá, v. 16, n. 4, p. 521-530, 2011. Disponível em: <http://www.scielo.br/pdf/pe/v16n4/a03v16n4>. Acesso em: 22 mar. 2017.

\section{CRESTANI, S. Organização do ensino de matemática na perspectiva do} desenvolvimento do pensamento teórico: uma reflexão a partir do conceito de divisão. 2016. 126 f. Dissertação (Mestrado em Educação) - Universidade do Sul de Santa Catarina, Tubarão, 2016.

DAVÍDOV, V. V. La enseñanza escolar y el desarrollo psíquico: investigación teórica y experimental. Moscú: Progreso, 1988. 1982. . Tipos de generalización en la enseñanza. 3. ed. Habana: Pueblo y Educación,

DAVÝDOV, V. V. et al. Matemática 2 ano: livro didático e de exercícios do ensino fundamental. Moscou: Vita-Press, 2012.

. Matemática 3 ano: livro didático e de exercícios do ensino fundamental. Moscou: Vita-Press, 2009.

GALDINO, A. P. S. $\mathbf{O}$ conhecimento matemático de estudantes do $3^{\circ}$ ano do ensino fundamental sobre o conceito de multiplicação: um estudo com base na teoria históricocultural. 2016. 110 f. Dissertação (Mestrado em Educação) - Universidade do Sul de Santa Catarina, Tubarão, 2016.

HOBOLD, E. S. F. Proposições para o ensino da tabuada com base nas lógicas formal e dialética. 2014. 199 f. Dissertação (Mestrado em Educação) - Universidade do Sul de Santa Catarina, Tubarão, 2014. Disponível em: < http://pergamum.unisul.br/pergamum/ pdf/108492_Ediseia.pdf>. Acesso em: 22 mar. 2017. 
LEFEBVRE, H. Lógica formal e lógica dialética. 5. ed. Rio de Janeiro: Civilização Brasileira, 1991.

MATOS, C. F. Modo de organização do ensino de matemática em cursos de pedagogia: uma reflexão a partir dos fundamentos da teoria histórico-cultural. 2017. 139 f. Dissertação (Mestrado em Educação) - Universidade do Sul de Santa Catarina, Tubarão, 2017.

PANOSSIAN, M. L. O movimento histórico e lógico dos conceitos algébricos como princípio para constituição do objeto de ensino da álgebra. 2014. 317 f. Tese (Doutorado em Educação) - Faculdade de Educação, Universidade de São Paulo, São Paulo, 2014.

ROSA, J. E. Proposições de Davydov para o ensino de matemática no primeiro ano escolar: inter-relações dos sistemas de significações numéricas. 2012. 244 f. Tese (Doutorado em Educação) - Universidade Federal do Paraná, Curitiba, 2012.

ROSA, J. E.; FLORES, M. M. O movimento conceitual da tabuada na história virtual Luer e seu foguete. Teoria e Prática da Educação, Maringá, v. 18, n. 2, p. 55-68, 2015. Disponível em: <http://periodicos.uem.br/ojs/index.php/TeorPratEduc/article/view/31444>. Acesso em: 22 mar. 2017.

ROSA, J. E.; DAMAZIO, A.; SILVEIRA, G. M. O sistema de numeração nas tarefas propostas por Davydov e seus colaboradores para o ensino de matemática. Bolema, Rio Claro, v. 28, n. 50, p. 1135-1154, 2014. Disponível em: < http://dx.doi.org/10.1590/19804415v28n50a07>. Acesso em: 22 mar. 2017.

ROSENTAL, M. M. Princípios de logica dialectica. Montevidéu: Pueblos Unidos, 1962. SHUARE, M. La psicologia soviéticat al como yo la veo. Moscú: Progreso, 1990.

STERNIN, A. O. O singular, o particular e o universal. In: ROSENTAL, M. M.; STRAKS, G. M. Categorías del materialismo dialéctico. México: Grijalbo, 1965. p. 257 - 297.

VIGOTSKI, L. S. A construção do pensamento e da linguagem. São Paulo: Martins Fontes, 2000.

Artigo recebido em 20/04/2015. Aceito em 02/11/2016.

Endereço para contato: Universidade do Sul de Santa Catarina, Avenida José Acácio Moreira, 787, Bairro Dehon, CEP 88704-900, Tubarão, SC, Brasil. 